Article

\title{
Hyperthermia-Triggered Gemcitabine Release from Polymer-Coated Magnetite Nanoparticles
}

\author{
G. R. Iglesias * (1) Felisa Reyes-Ortega ${ }^{(\mathbb{D}}$, B. L. Checa Fernandez ${ }^{(\mathbb{D})}$ and Ángel V. Delgado \\ Department of Applied Physics, Facultad de Ciencias, Campus Fuentenueva, School of Sciences, and MNAT \\ Unit of Excellence, University of Granada, 18071 Granada, Spain; felisareyes@ugr.es (F.R.-O.); \\ lunachecaf@gmail.com (B.L.C.F.); adelgado@ugr.es (A.V.D.) \\ * Correspondence: iglesias@ugr.es; Tel.:+34-958-242-734
}

Received: 5 February 2018; Accepted: 3 March 2018; Published: 6 March 2018

\begin{abstract}
In this work a combined, multifunctional platform, which was devised for the simultaneous application of magnetic hyperthermia and the delivery of the antitumor drug gemcitabine, is described and tested in vitro. The system consists of magnetite particles embedded in a polymer envelope, designed to make them biocompatible, thanks to the presence of poly (ethylene glycol) in the polymer shell. The commercial particles, after thorough cleaning, are provided with carboxyl terminal groups, so that at physiological $\mathrm{pH}$ they present negative surface charge. This was proved by electrophoresis, and makes it possible to electrostatically adsorb gemcitabine hydrochloride, which is the active drug of the resulting nanostructure. Both electrophoresis and infrared spectroscopy are used to confirm the adsorption of the drug. The gemcitabine-loaded particles are tested regarding their ability to release it while heating the surroundings by magnetic hyperthermia, in principle their chances as antitumor agents. The release, with first-order kinetics, is found to be faster when carried out in a thermostated bath at $43{ }^{\circ} \mathrm{C}$ than at $37^{\circ} \mathrm{C}$, as expected. But, the main result of this investigation is that while the particles retain their hyperthermia response, with reasonably high heating power, they release the drug faster and with zeroth-order kinetics when they are maintained at $43{ }^{\circ} \mathrm{C}$ under the action of the alternating magnetic field used for hyperthermia.
\end{abstract}

Keywords: biocompatible polymer; drug delivery; gemcitabine; magnetic hyperthermia; magnetic nanoparticles

\section{Introduction}

The interest of nanoparticle (NP) science and technology spreads over a large number of fields, biomedicine being one where applications are becoming closest to everyday life [1-6]. The wide range of nanostructures built with that purpose, the practically unlimited functionalization routes, and, of course, the correct size scale in comparison with cells and their membranes may partially account for an explanation to these facts. Among the many nanoparticles designs, either organic, inorganic, or mixed, those that are based on magnetic iron oxides (mostly magnetite and maghemite), hence being called magnetic nanoparticles (MNPs), have seen their possibilities multiplied because of their magnetic response. It is specifically desired to have a paramagnetic-like behavior, so that the particles are only magnetized in the presence of the field, with no remanence or coercivity. They are then denominated SPIONs (superparamagnetic iron oxide nanoparticles), and they have been proposed to be part of disease diagnose and treatment (or theranostics), very particularly in the case of solid tumors [7-17]. It is precisely their response to either dc or ac magnetic fields that determines the fields of biomedical applications of MNPs. One of them is drug delivery: the particles would be part of so-called magnetic vectors, which are loaded with a chemotherapeutic drug and functionalized in such a way that they can mostly escape from the cells of the immune system, in addition to being able 
to specifically interact with the target tumor cells. A non-homogeneous, externally applied magnetic field can be used to drive the particles to their site of action, or, at least, keep them there after being transported by the blood stream [11,18-22]. Many in vitro and in vivo tests have demonstrated the feasibility of this approach, but no formulation based on MNPs for drug delivery has been approved to date. In contrast, Drug Agencies have approved formulations based on MNPs, to be used as contrast agents in magnetic resonance imaging [23-26].

A very promising application field is that of magnetic hyperthermia. When a suspension of magnetic particles is subjected to an alternating magnetic field of suitable frequency and strength, heat is released which will warm up the suspension and its surroundings. If applied to particles that are embedded in a tumor, and if the temperature is raised to $42-43^{\circ} \mathrm{C}$ for at least half an hour, the heating will produce the death of the tumor cells (healthy ones can withstand this temperature safely), and eventually provoke the disappearance of the tumor or at least help other therapeutic approaches in that task [27-37]. The mechanism by which the heating occurs depends on the particle size: in the case of SPIONs, both eddy currents and hysteresis losses can be neglected, and only Néel and/or Brownian (or viscous) relaxations are possible $[28,36,38,39]$ : the former refer to the oscillations of the magnetic moment of the NP back and forth between two easy directions of magnetization, in an otherwise immobile particle. The second mechanism involves the rotational motion of the particle itself in the suspending fluid. Both of the processes can be present at a time, depending on the frequency-size combination [36,40], and in the two of them there is a lag between magnetization and field (that is, an imaginary component of the susceptibility), ultimately being responsible for the heat loss.

There is indeed the possibility of designing MNPs aimed at being used in more than one of the cited applications. For instance, contrast in MRI can help in locating the distribution of magnetic particles while applying hyperthermia [41-44]. Closer to the objectives of the present work is the use of the magnetic particles in nanostructures that are aimed at the simultaneous application of hyperthermia and drug delivery in-situ, an application denominated thermotherapy by some authors [45]. The idea is double: the vehicles can deliver the drug while producing magnetic hyperthermia, and, furthermore, the latter can trigger or speed up the drug release. It has been shown to work as expected in a number of combinations, for instance doxorubicin on different magnetic substrates, including magnetite/thermoresponsive polymer [46-48], magnetite/phospholipid/poly (etilenglicol) [49], or magnetite/poly(ethylene imine)/poly(styrene sulfonate)/PEG [50], to mention a few.

In this paper, the commercial magnetic particles used consist of a magnetite core and a polymeric envelope, a co-polymer of methyl methacrylate/ethylene glycol dimethacrylate/hydroxyl ethyl methacrylate. We describe the procedure that is used for transforming them into suitable substrates for the electrostatic adsorption of gemcitabine (GEM). This is an antitumor agent that is employed extensively against several human cancers [51-56], including ovarian, lung, pancreatic, bladder, urothelial, and breast cancer. Furthermore, this drug has been approved by FDA [57] and it is the most prescribed anticancer drug worldwide, alone or in combination with other chemotherapeutic agents, namely doxorubicin $[58,59]$. While the latter has been widely studied as a single antitumor agent, more scarce investigations have been carried out with gemcitabine. For this reason, this work has focused on this drug, in an attempt to broaden our understanding of the delivery mechanism of this drug. The biocompatible polymer-coated MNPs were loaded with GEM and their release rate investigated in three cases: suspensions kept in a thermostated bath at $37^{\circ} \mathrm{C}$ or $43^{\circ} \mathrm{C}$, or were subjected to magnetic hyperthermia at $43^{\circ} \mathrm{C}$ for specified time intervals. It appears that the latter brings about a substantial improvement in the drug release rate, and this constitutes a promising result regarding the design of multi-functional platforms for cancer therapy. 


\section{Materials and Methods}

\subsection{Materials}

MagP ${ }^{\circledR}-\mathrm{OH}$ particles were purchased from NanoMyP (Granada, Spain). According to the manufacturer, these composite particles contain magnetite NPs that are coated with a polymer shell (Scheme 1) composed of $54 \mathrm{wt} \%$ methyl methacrylate, $31 \mathrm{wt} \%$ ethylene glycol dimethacrylate, and 15 wt \%, hydroxyl ethyl methacrylate, or poly(MMA-co-EGDMA-co-HEMA). The terminal monomers are MMA (bound to the particles by emulsion polymerization), and HEMA (providing surface $\mathrm{OH}$ groups to the composites). The EGDMA polymer acts as crosslinker and determines the thickness of the layer and adds biocompatibility to the particles, as PEG is recognized as one of the best options for avoiding opsonization and subsequent attack to the particles by the cells of the mononuclear phagocyte system $[49,60,61]$. The original particles are coated with a surfactant (SDS) in order to facilitate their stability. This layer was eliminated to the maximum possible extent by repeated centrifugation at $14,000 \times \mathrm{rpm}$ and redispersion in water.

N-hydroxysuccinimide (NHS) (98\%), 4-(dimethylamino) pyridine (DMAP) (99\%), dichloromethane anhydrous (DCM), and phosphate buffered saline (PBS) tablets were purchased from Sigma-Aldrich (St. Lois, MO, USA). Gemcitabine hydrochloride was acquired from Adooq Bioscience LLC (Irvine, CA, USA). Water that was used in the preparation of the solutions was deionized in a Milli-Q Academic (Madrid, Spain) device, with conductivity of $0.054 \mu \mathrm{S} / \mathrm{cm}$ at $25^{\circ} \mathrm{C}$.

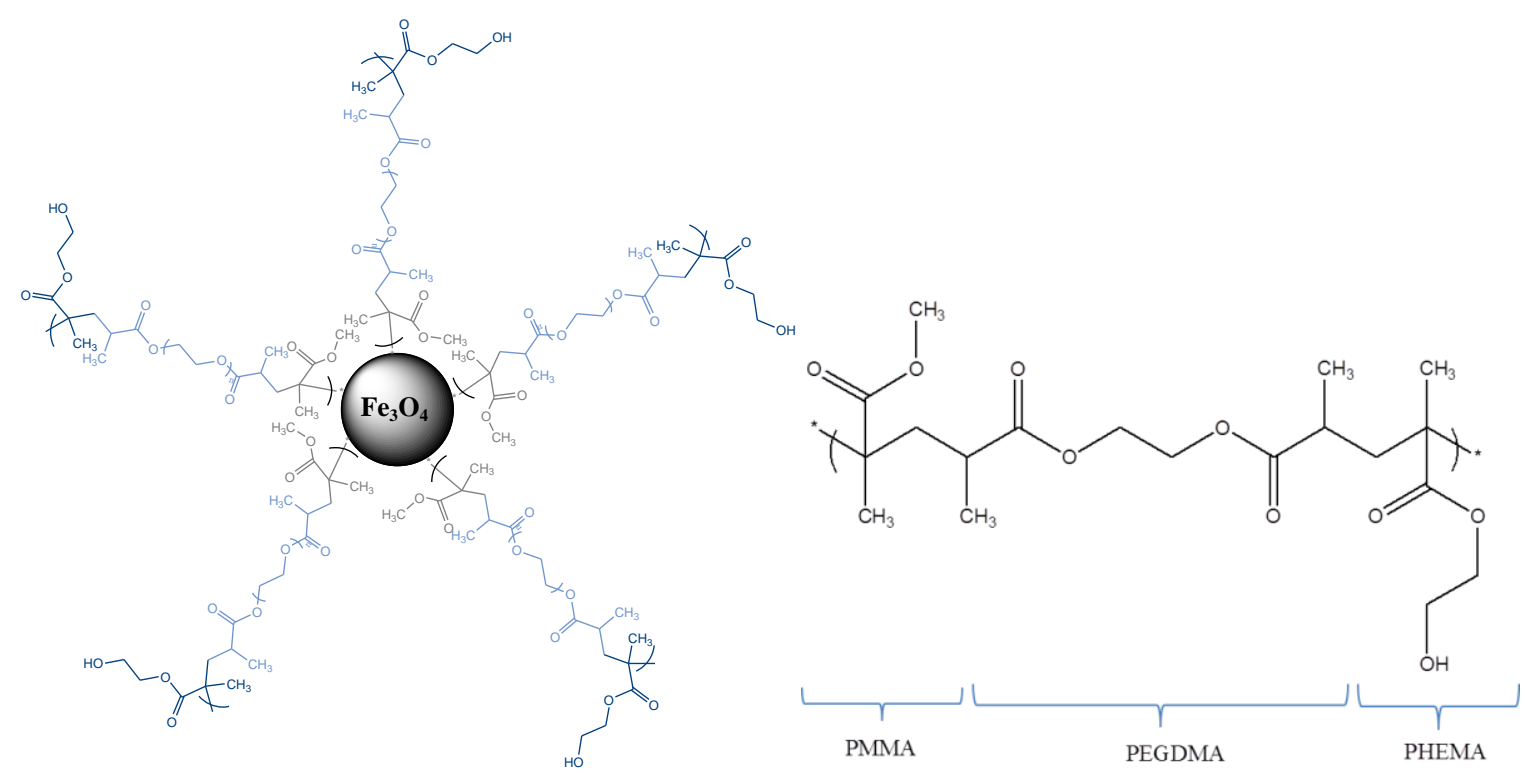

Scheme 1. Chemical structure of the MagP ${ }^{\circledR}-\mathrm{OH}$ magnetic nanoparticles.

\subsection{Methods}

\subsubsection{Functionalization with - $\mathrm{COOH}$ Terminal Groups}

In order to increase the surface charge of the $\mathrm{MagP}^{\circledR}-\mathrm{OH}$ at physiological $\mathrm{pH}$, thus being likely improving the ionic attachment, 2 equivalents of NHS (5.3 mg), 1 equivalent of MagP ${ }^{\circledR} \_\mathrm{OH}(100 \mathrm{mg})$ and 1 equivalent of DMAP $(2.8 \mathrm{mg}$ ) were added to a flask that was previously purged with nitrogen. Then, $20 \mathrm{~mL}$ of dry DCM was added under the nitrogen atmosphere, and the mixture was mechanically stirred for $24 \mathrm{~h}$ at room temperature. Afterwards, the particles were magnetically decanted and washed several times with a mixture of ethanol and distilled water (1:1), and finally dried at $60{ }^{\circ} \mathrm{C}$ in an oven. The resulting particles will have terminal carboxylic groups (and hence will be denominated 
MagP-COOH hereafter) and hence higher charge surface than the particles with terminal hydroxyl groups, allowing for higher ionic attachment efficiency with positive charged drugs.

\subsubsection{Adsorption of Gemcitabine to MagP-COOH}

GEM was incorporated to the MagP-COOH particles by dispersing them in an aqueous solution of the drug. Concisely, different amounts of $\mathrm{MagP}-\mathrm{COOH}$ were dispersed into $1 \mathrm{~mL}$ of an aqueous $1 \mathrm{mM}$ GEM solution, under mechanical stirring at room temperature, for $18 \mathrm{~h}$. Then, the particles with the adsorbed GEM were centrifuged at $14,000 \times \mathrm{rpm}$ for $30 \mathrm{~min}$ to remove the supernatant. The same procedure was used for the repeated washing of the particles with Milli-Q water. The final step consisted of freeze-drying the GEM-coated particles in order to obtain the loaded magnetic vectors.

\subsubsection{Morphology and Size Distribution}

The morphology of the nanoparticles was observed by transmission electron microscopy (TEM) using a LIBRA 120 Plus Carl Zeiss microscope (Oberkochen, Germany). TEM images were analyzed with J-Image software in order to calculate the particle size distribution of the dried NPs. These results were compared with data obtained by DLS, using a Nano-ZS apparatus (Malvern Instruments, Worcestershire, UK). All of the measurements were performed at $1 \mathrm{mg} / \mathrm{L}$ in Milli-Q water at $25^{\circ} \mathrm{C}$.

\subsubsection{Electrophoretic Mobility and Zeta Potential}

Electrophoretic mobility measurements were carried out in the Nano-ZS at $25^{\circ} \mathrm{C}$, in suspensions with about $0.01 \% w / v$ solids concentration and a constant ionic strength of $5 \mathrm{mM} \mathrm{KNO}_{3}$. The $\mathrm{pH}$ value of the suspensions was then adjusted by adding a suitable amount of $\mathrm{KOH}(0.01$ or $0.1 \mathrm{M})$ or $\mathrm{HNO}_{3}$ $(0.01$ or $0.1 \mathrm{M})$. For each suspension, five measurement runs were taken, with 11 cycles in each run. The zeta potential, $\xi$, was obtained from the O'Brien and White electrophoresis theory [60].

\subsubsection{ATR-FTIR Characterization}

FTIR spectra were obtained in the Attenuated Total Reflection mode (ATR-FTIR) in a JASCO 6200 FT-IR (Tokyo, Japan) spectrometer with SPECTRA MANAGER V2 software. Samples were analyzed without further treatment at room temperature with 50 scans and a resolution of $4 \mathrm{~cm}^{-1}$.

\subsubsection{Thermogravimetric Analysis}

Thermogravimetric analysis (TGA) was performed on a TGA-50H SHIMADZU (Kyoto, Japan) device with vertical oven and a maximum precision of $0.001 \mathrm{mg}$. Samples were analyzed under $50 \mathrm{~mL} / \mathrm{min}$ nitrogen flow, and at a heating rate of $10{ }^{\circ} \mathrm{C} / \mathrm{min}$, from 30 to $900{ }^{\circ} \mathrm{C}$.

\subsubsection{Magnetic Properties}

Magnetization cycles were obtained at room temperature in an MPMS-XL SQUID magnetometer (Quantum Design, San Diego, CA, USA).

\subsubsection{Magnetic Hyperthermia and Specific Absorption Rate Determination}

Magnetic hyperthermia was implemented using an AC current generator built with a Royer-type oscillator. An eight turn coil (20 mm in diameter and $45 \mathrm{~mm}$ in length) that was made of $6 \mathrm{~mm}$ water cooled copper tube was connected to the oscillator in parallel with different combinations of capacitors, so that the field frequencies were changed, with fixed values of 185, 206, 236, and $285 \mathrm{kHz}$. The current through the coil (typically $7 \mathrm{~A}$ ) was selected to reach a magnetic field amplitude of $16.2 \mathrm{kA} / \mathrm{m}$ (20 mT magnetic induction in air), measured at the center of the coil with a NanoScience Laboratories Ltd., Probe (Newcastle, UK), with $10 \mu \mathrm{T}$ resolution.

The hyperthermia efficiency of the particles was quantified by measuring the rate of temperature increase registered with an optical fiber thermometer (Optocon AG, Dresden, Germany). The fiber 
probe was placed into a $5 \mathrm{~mL}$ Eppendorf tube containing $0.5 \mathrm{~mL}$ of a $10 \mathrm{mg} / \mathrm{mL}$ suspension of the magnetic nanoparticles, previously pre-thermostated at $37^{\circ} \mathrm{C}$; this was also the temperature that was chosen for the water circulating inside the copper coil. The tube was in turn inserted in the coil, and was thermally insulated from it by using a Styrofoam chamber. From the initial slope of the temperature vs. time dependence (typically, the first $30 \mathrm{~s}$ after switching the field on), $d T / d t$, the specific absorption rate, $S A R$, was obtained, as follows [28,62]:

$$
S A R=\frac{C V_{s}}{m} \frac{d T}{d t}
$$

where $C$ is the volume specific heat capacity of the sample $\left(C_{\mathrm{H}_{2} \mathrm{O}}=4185 \mathrm{~J} / \mathrm{LK}\right), V_{s}$ is the sample volume $(0.5 \mathrm{~mL}$ in the reported experiments), and $m$ is the mass of solids in the sample $(5 \mathrm{mg})$. If a linear relationship between the sample magnetization and the field is assumed (a reasonable hypothesis for the small field amplitude used), the power density (per unit volume of particles) of heating can be calculated as:

$$
\rho_{W}=\mu_{0} \pi f \chi^{\prime \prime} H_{0}^{2}
$$

in terms of the imaginary component of the magnetic susceptibility, $\chi^{\prime \prime}$, of the particles $[27,28,36,63,64]$. Hence, the $S A R$ is found to depend on the square of the magnetic field and its frequency. For this reason, some authors prefer to describe the phenomenon for a given sample in terms of the so-called intrinsic loss power or ILP [29], given by:

$$
I L P=\frac{S A R}{f H_{0}^{2}}
$$

Typically, ILP is given in units of $\mathrm{nHm}^{2} / \mathrm{kg}\left(H_{0}\right.$ in $\mathrm{kA} / \mathrm{m}, f$ in $\mathrm{kHz}$, and $S A R$ in $\left.\mathrm{W} / \mathrm{kg}\right)$.

\subsubsection{Drug Loading and Release}

The drug adsorption on the particles was evaluated by means of optical absorbance determinations at $268 \mathrm{~nm}$ wavelength in a $6705 \mathrm{UV} /$ Vis JENWAY spectrophotometer (Staffordshire, UK). The amount of non-adsorbed drug recovered in the external aqueous phase after centrifugation was quantified using a calibration line that was obtained from absorbance measurements in solutions of different concentrations of GEM in PBS. The drug release from loaded particles was also determined spectrophotometrically, as follows: $20 \mathrm{mg}$ of particles was dispersed in $5 \mathrm{~mL}$ of PBS (pH 7.4); at specified time intervals, particles were magnetically decanted, then $0.5 \mathrm{~mL}$ of the supernatant was removed and replaced by the same volume of pure PBS. The removed aliquot was then centrifuged at $14,000 \times \mathrm{rpm}$ for $30 \mathrm{~min}$ at room temperature, the absorbance of the supernatant was measured, and the amount of GEM was calculated from the calibration line. This allowed for calculating the amount of GEM released. Experiments were first run in the absence of any applied magnetic field, at two temperatures: $37^{\circ} \mathrm{C}$ (physiological) and $43{ }^{\circ} \mathrm{C}$ (end temperature set in the hyperthermia experiments). The release study with the AC magnetic field applied was similarly carried out, but controlling the magnetic field strength to ensure a constant temperature of $43.0 \pm 0.5^{\circ} \mathrm{C}$.

\section{Results and Discussion}

\subsection{Morphology and Particle Size Distribution}

$\mathrm{MagP}^{\circledR}-\mathrm{OH}$ particles were observed in the TEM after surfactant removal. As shown in Figure 1, they can be described as a polymer envelope encapsulating the magnetite cores.

The histogram of the particle size distribution deduced from the TEM images (Figure 2a), reveals a mean $( \pm \mathrm{SD})$ particle diameter of $76 \pm 13 \mathrm{~nm}$. The hydrodynamic diameter $D_{h}$ of these particles when they were dispersed in water was measured by DLS and the resulting size distribution by number is shown in Figure 2b; from this, the mean diameter results $D_{h}=86 \pm 11 \mathrm{~nm}$ with a polydispersity 
index (PDI) of 0.26. As it happens usually, the hydrodynamic diameter is somewhat higher than that obtained by TEM due to the hydration of the hydrophilic outmost polymer layer, and to the possibility of some extent of particle aggregation in the aqueous medium.

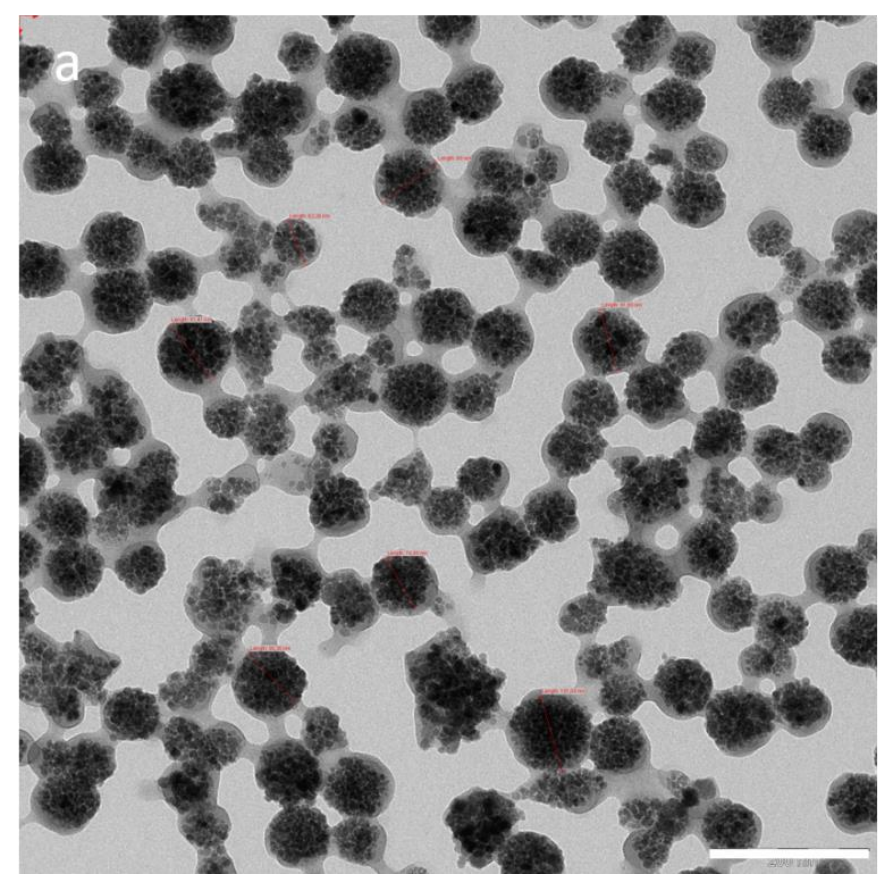

Figure 1. (a) TEM image of MagP ${ }^{\circledR}-\mathrm{OH}$ particles. Scale bar: $200 \mathrm{~nm}$. (b) Detail of a single particle. Scale bar is $20 \mathrm{~nm}$. (c) MagP ${ }^{\circledR}-\mathrm{OH}$ particle scheme.
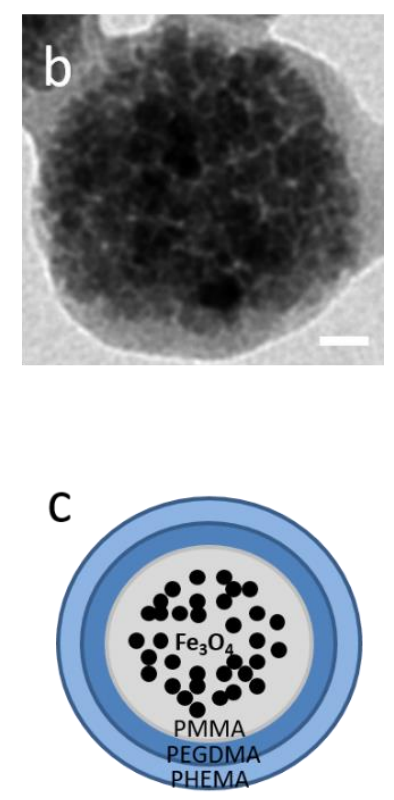
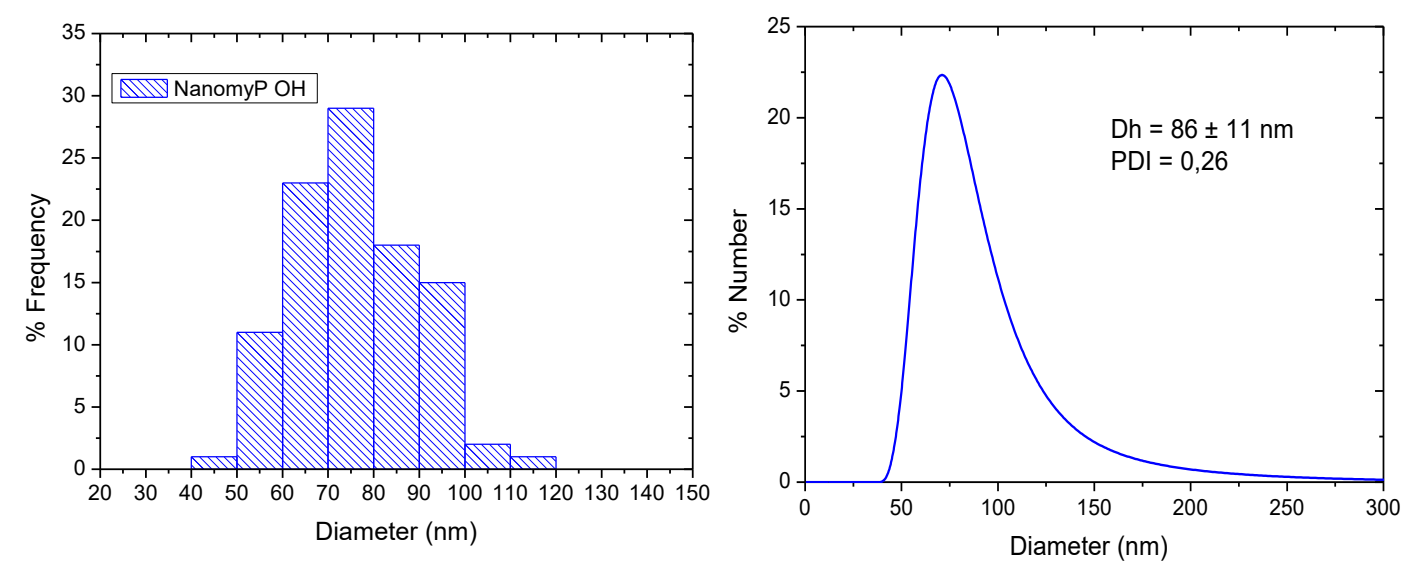

Figure 2. Left: Diameter histogram of the MagP ${ }^{\circledR}-\mathrm{OH}$ particles calculated from TEM images. Right: size distribution by number, calculated from DLS data.

\subsection{Zeta Potential}

The commercial MagP ${ }^{\circledR}-\mathrm{OH}$ NPs showed a negative zeta potential of $-27.7 \pm 0.5 \mathrm{mV}$, before being washed to remove the SDS surfactant. After such removal, the zeta potential was measured at different $\mathrm{pHs}$ to determine the surface charge of the particles without the surfactant influence. As it is shown in Figure 3, the isoelectric point of $\mathrm{Mag} \mathrm{P}^{\circledR}-\mathrm{OH}$ was obtained at $\mathrm{pH}$ 6.9. This characterization allows us to select the optimal $\mathrm{pH}$ value to carry out the electrostatic attachment of the drug, since the form used, GEM hydrochloride is positively charged and stable at any $\mathrm{pH}$ between that corresponding to the $p K_{a}(=3.6)$ of GEM, and $\mathrm{pH} 10$, above which the drug undergoes degradation $[65,66]$. Therefore, 
further drug loading and release experiments were carried out at physiological $\mathrm{pH}$, whereby magnetite is negatively charged and the drug is positive and quite stable.

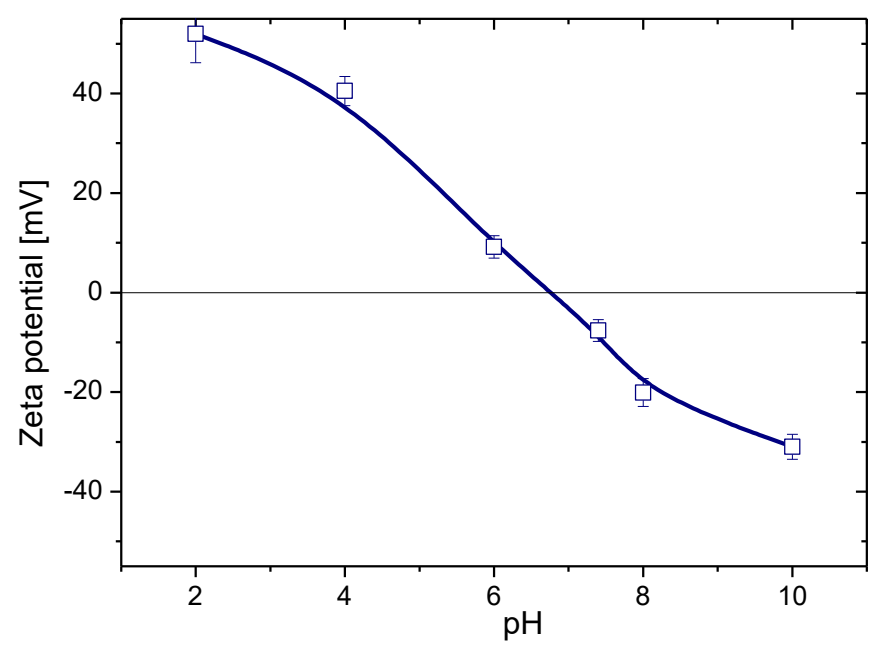

Figure 3. Zeta potential of $\mathrm{MagP}^{\circledR}-\mathrm{OH}$ versus $\mathrm{pH}$ in $5 \mathrm{mM} \mathrm{KNO}_{3}$.

Figure 4 shows the zeta potential distribution of the commercial NPs $\left(\mathrm{MagP}^{\circledR}-\mathrm{OH}\right)$ before and after the carboxylation of the particles $\left(\mathrm{MagP}^{\circledR}-\mathrm{COOH}\right)$. It is observed that the zeta potential average at physiological $\mathrm{pH}$ becomes more negative (from $-7.6 \pm 0.2 \mathrm{mV}$ to $-17.5 \pm 0.3 \mathrm{mV}$ ) after carboxylation, and this will promote a higher ionic attachment of the drug. This sort of loading is confirmed by the zeta potential becoming less negative $(-12.4 \pm 0.3) \mathrm{mV}$ after contact of the $\mathrm{MagP}^{\circledR}-\mathrm{COOH}$ particles (23 mg) with $1 \mathrm{~mL}$ of GEM $1 \mathrm{mM}$ aqueous solution, under mechanical stirring for $18 \mathrm{~h}$.

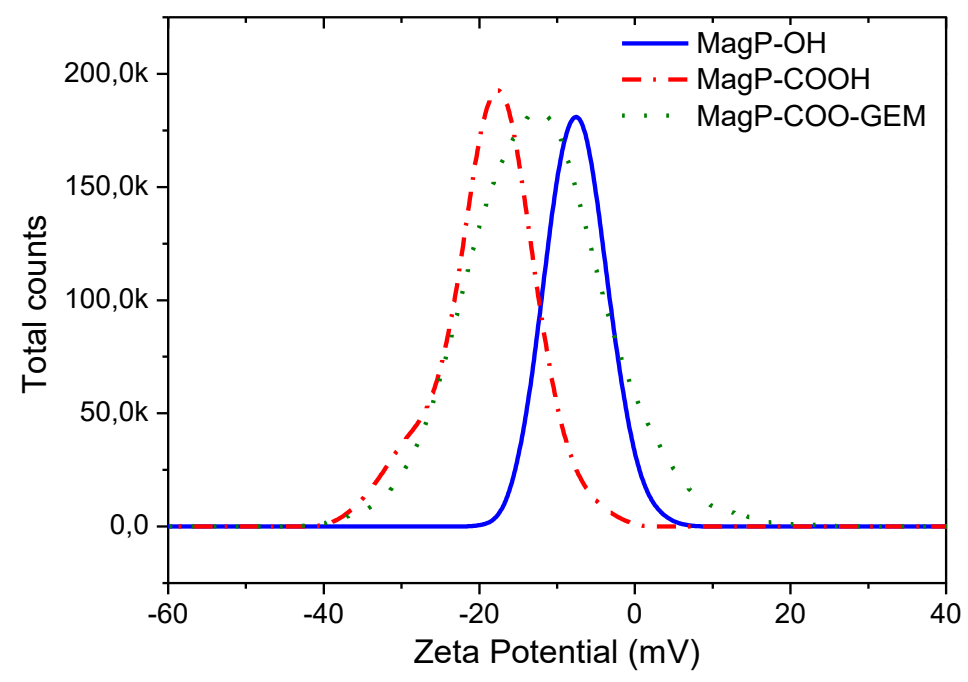

Figure 4. Zeta potential distribution of $\mathrm{MagP}-\mathrm{OH}$, MagP-COOH and Gemcitabine loaded $\mathrm{MagP}-\mathrm{COOH}$ systems.

\subsection{Drug Loading}

As mentioned, from the absorbance of the supernatants of the GEM solutions containing suitable amounts of particles, the amount of drug loaded on the particles could be evaluated. Different GEM/MNPs ratios were tested and the results in Table 1 show that the amount of adsorbed GEM when the ratio is $33.3 \mathrm{mg} / \mathrm{g}$ was $13.9 \%$, which means $14.3 \mu \mathrm{M}$ drug/g MNPs. This loading is similar or even higher than those that were reported in the literature regarding incorporation of 
this drug onto different polymeric NPs [67-69]. It is worth mentioning that increasing the initial drug/MNPs ration does not improve the amount of GEM adsorbed (Table 1), which indicates that some sort of electrostatic saturation binding was reached for the concentrations studied. Therefore, the optimal ratio of $33.3 \mathrm{mg}$ GEM/g MNPs was used for further characterization and release studies.

Table 1. GEM adsorbed on MagP-COOH NPs for different initial drug/MNPs ratios.

\begin{tabular}{ccc}
\hline $\begin{array}{c}\text { Initial Drug/MNPs Ratio } \\
\text { (mg/g) }\end{array}$ & $\begin{array}{c}\text { Adsorbed GEM } \\
\text { (mg/g MNPs) }\end{array}$ & $\begin{array}{c}\text { Fraction of Adsorbed Drug } \\
(\mathbf{\%})\end{array}$ \\
\hline 33.3 & 4.3 & 13.9 \\
66.7 & 4.0 & 6.0 \\
100 & 3.0 & 3.0 \\
\hline
\end{tabular}

\subsection{ATR-FTIR Characterization}

Figure 5 shows the infrared spectra of the three kinds of particles that are used in this work (original MagP ${ }^{\circledR}-\mathrm{OH}, \mathrm{GEM}$ and drug-loaded MagP-COO-GEM). Note the presence in the first ones of both magnetite $\left(\mathrm{Fe}_{3} \mathrm{O}_{4}\right)$ and the methacrylate polymers (PMMA, PEGDMA, PHEMA). The characteristic bands in the range $3200-3600 \mathrm{~cm}^{-1}$ are attributed to the stretching of the hydroxyl $(\mathrm{OH})$ groups of the PHEMA component. The bands at 2972 and $2927 \mathrm{~cm}^{-1}$ correspond to the $\mathrm{C}-\mathrm{H}$ stretching vibration belongs to the methyl and methylene groups of the polymers, the bands at 1729 and $1636 \mathrm{~cm}^{-1}$ are related to the stretch of the ester carboxyl groups $(\mathrm{C}=\mathrm{O})$ of the PMMA, PEGDMA, and PHEMA respectively, the bands to 1452 and $1380 \mathrm{~cm}^{-1}$ are attributed to the bending of $\mathrm{C}-\mathrm{H}$, the bands at 1264, 1157, and $1087 \mathrm{~cm}^{-1}$ belongs to the stretching vibration of the ether groups (C-O) of the methacrylate polymers, band at $1048 \mathrm{~cm}^{-1}$ is attributed to the stretching vibration of ether bonds of the polymeric chain belongs to PEGDMA, and the band at $880 \mathrm{~cm}^{-1}$ correspond to the single bond deformation vibration of ether groups $(\mathrm{C}-\mathrm{O})$. The presence of magnetite is evident due to bands in the range of $570-630$ and at $460 \mathrm{~cm}^{-1}$, that are due to the stretching vibration bands associated to the iron-oxygen bonds $(\mathrm{Fe}-\mathrm{O})$ in the octahedral and tetrahedral sites of the oxide structure.

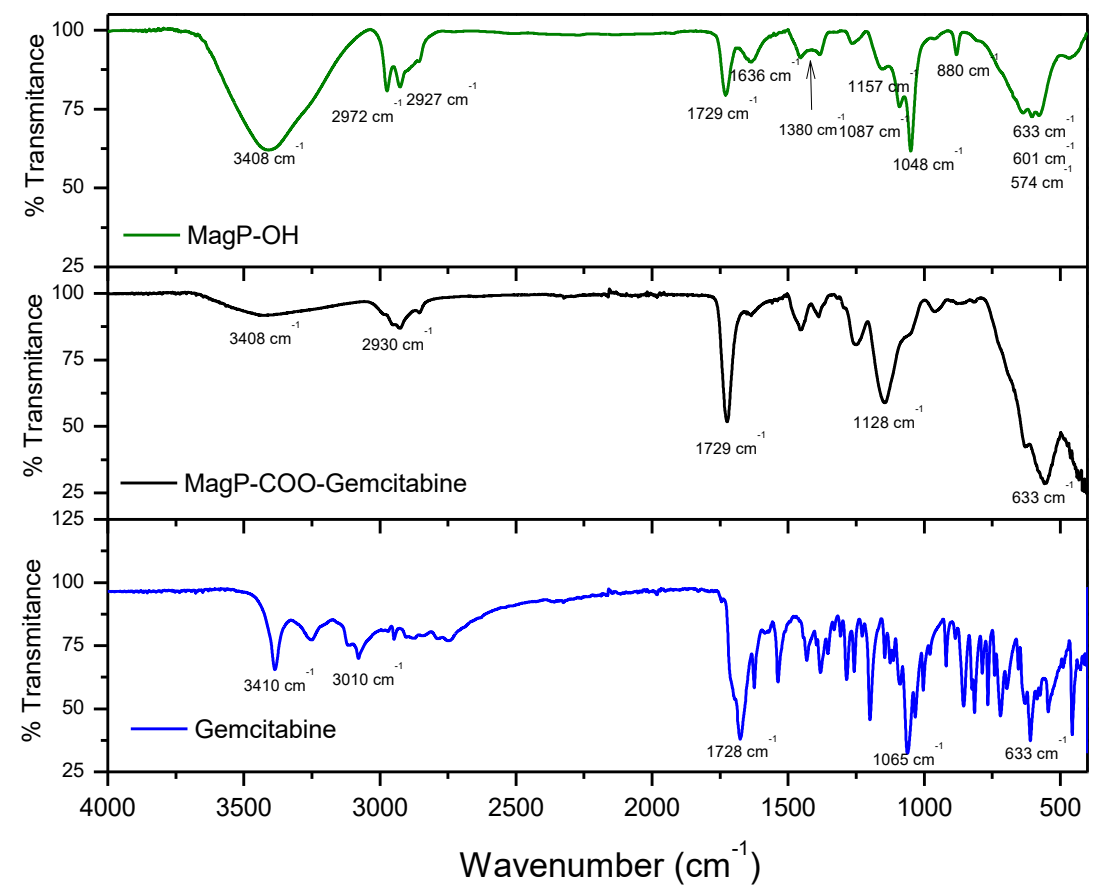

Figure 5. ATR-FTIR spectra of MagP-OH nanoparticles, MagP-COO-GEM nanoparticles, and GEM drug. 
The ATR-FTIR spectrum of the MagP-COO-GEM shows a noticeable decrease in the -OH band that is situated at $3200-3600 \mathrm{~cm}^{-1}$, demonstrating the efficacy of the previous carboxylation of these groups. Besides, the ionic reaction between $\mathrm{MagP}-\mathrm{COO}^{-}$and $\mathrm{GEM}$ was verified by the increase in the $\mathrm{C}=\mathrm{O}$ band at $1729 \mathrm{~cm}^{-1}$ and the bands modification in the range $500-1500 \mathrm{~cm}^{-1}$, where pure GEM shows its characteristic bands.

\subsection{Thermogravimetric Analysis}

A thermogravimetric analysis was used to evaluate the thermal stability of the magnetic particles, as well as to check the polymer/magnetite weight ratio and the polymer components. The thermogram of the carboxylated nanoparticles (MagP-COOH) is shown in Figure 6. The weight loss curve shows a total degradation of $41.6 \mathrm{wt} \%$ up to $600{ }^{\circ} \mathrm{C}$, which corresponds to the polymeric component of the nanoparticles. The inorganic residue of $58.4 \%$ left, according to the TGA analysis corresponds to the magnetite component. Between 600 and $800{ }^{\circ} \mathrm{C}$, the observed weight loss has been associated to magnetite reduction to $\alpha-\mathrm{Fe}$ and $\mathrm{FeO}$ [70]. The dotted curve shows the weight percentage loss rate versus temperature (first derivative of the weight loss curve), showing three maximum degradation temperatures for the polymeric coating at $265^{\circ} \mathrm{C}, 329^{\circ} \mathrm{C}$ and $387^{\circ} \mathrm{C}$, which correspond to PHEMA, PEGMA, and PMMA respectively [71-73]. These degradation steps allow for the quantification of the weight percentage of each polymer in the nanoparticle system, being $11 \mathrm{wt} \%$ of PHEMA, $30 \mathrm{wt} \%$ of PEGMA, and $59 \mathrm{wt} \%$ of PMMA.

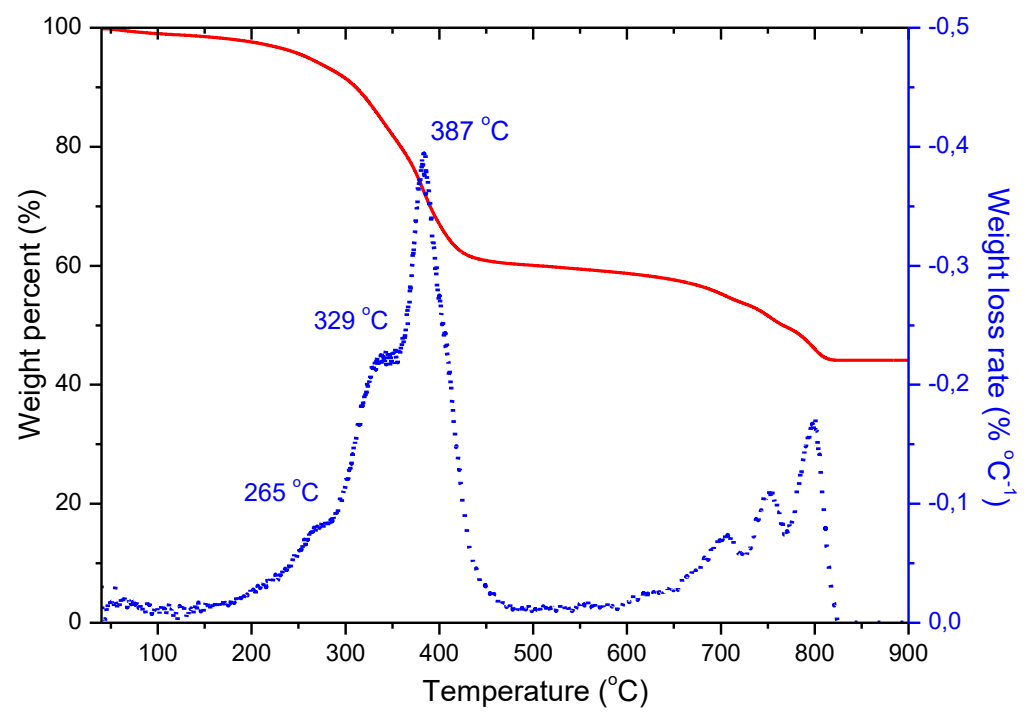

Figure 6. Thermogram of the magnetic nanoparticles.

\subsection{Magnetization and Hyperthermia}

The magnetization of MagP ${ }^{\circledR}-\mathrm{OH}$ NPs as a function of the magnetic field is represented in Figure 7. The superparamagnetic behavior of the core magnetite NPs manifests in the composite nanostructures, although the presence of the non-magnetic polymeric envelope reduces the saturation magnetization from that of bulk magnetite $(90 \mathrm{emu} / \mathrm{g})$ to a value close to $35 \mathrm{emu} / \mathrm{g}$. Such kind of a reduction has been previously reported in literature $[74,75]$ and justified by the contribution of the polymer layers and the limited magnetic order at the magnetic NP/polymer interfaces, very abundant in our particles (Figure 1).

Figure 8a shows the time evolution of the temperature of a suspension of MNPs before loading the drug, for different frequencies of the field $(285,236,206$, and $185 \mathrm{kHz})$. It is possible to observe that the time needed for reaching $41^{\circ} \mathrm{C}$ decreases with frequency. Thus, for the highest frequency, it is found a rapid increase of temperature from 37 to $41^{\circ} \mathrm{C}$ in less than a minute, which is ideally desired for cancer 
treatment application. Pure water baseline is added as reference, showing the negligible effect of Joule heating of the copper coil in the data. The SAR and ILP values are represented in Figure $8 \mathrm{~b}$. Note that the former reaches values that are in the high range of those reported in the literature, and that they increase with the field frequency, as mentioned. On the contrary, the intrinsic loss power is frequency independent, in agreement with the predictions of Equation (3). The analysis of these results suggests that the particles will be a useful tool to produce local heating and generate enough heat as to locally rise the temperature of the tumor tissue for the effective hyperthermia treatment.

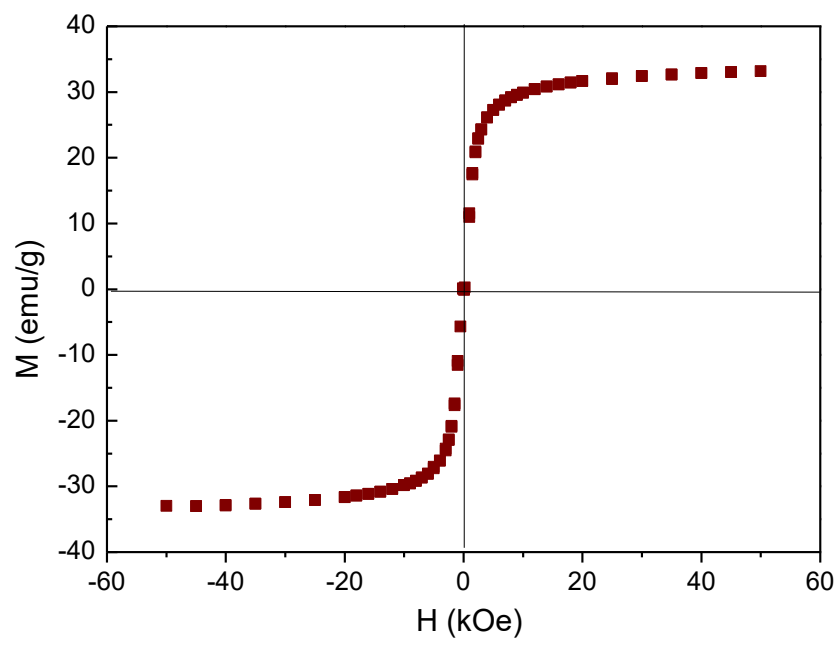

Figure 7. Magnetization curve of MagP ${ }^{\circledR}-\mathrm{OH}$ magnetic nanoparticles.
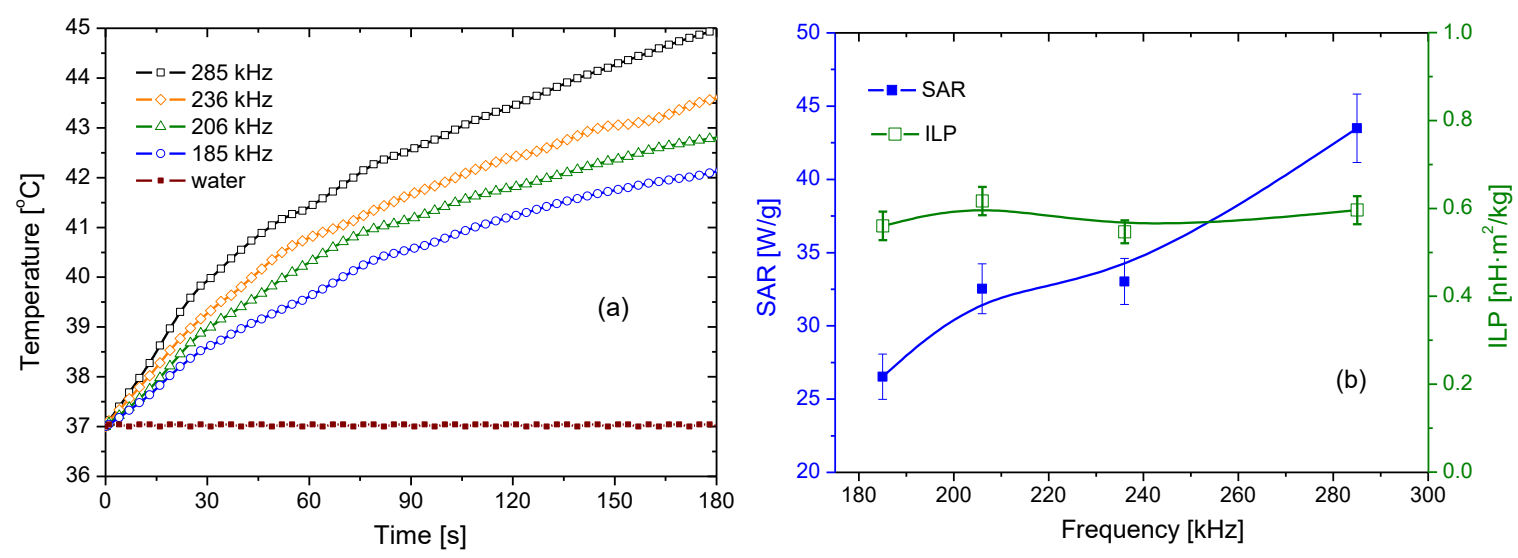

Figure 8. (a) Time evolution of the temperature for different frequencies in hyperthermia experiments performed with suspensions containing $10 \mathrm{mg} / \mathrm{mL}$ of $\mathrm{MagP}{ }^{\circledR}-\mathrm{OH}$. (b) SAR and ILP evaluation. The field amplitude was $H_{0}=16.2 \mathrm{kA} / \mathrm{m}$ in all the cases.

\subsection{Drug Release}

GEM release studies were performed in PBS buffer at $\mathrm{pH} 7.4$, which mimics the physiological conditions. Drug release was tested at controlled temperatures of $37 \pm 1{ }^{\circ} \mathrm{C}$ and $43 \pm 1{ }^{\circ} \mathrm{C}$. A third release test was carried out using the AC magnetic field that is applied in hyperthermia, so as to evaluate the potential triggering effect of the field on the release profile of the drug. A typical hyperthermia and drug release experiment is shown in Figure 9. The nanoparticles that are loaded with the drug were exposed to the magnetic field for $30 \mathrm{~min}[76,77]$. After a rapid increase in temperature, the system was stabilized between $43^{\circ} \mathrm{C}$ and $44^{\circ} \mathrm{C}$ by manually controlling the magnetic field strength. Drug release results are plotted in Figure $9 \mathrm{~b}$. As observed, the fastest release profile of GEM was obtained when the magnetic field was applied, allowing for the complete release of the drug in less 
than $4 \mathrm{~h}$. The kinetic release in this case follows a quasi-zeroth order profile [78], with an initial delay in the drug release, probably due to the time needed to reach the optimal triggering temperature. The released amount $R(t)$ can be fitted to the Equation (4):

$$
R(t)=R(0)+k_{0} t
$$

where $R(0)$ is the initial amount of drug in the solution and $k_{0}$ is the zeroth-order release constant expressed in units of concentration/time, which was found to be $27 \mu \mathrm{g} / \mathrm{mL} \cdot \mathrm{h}$. This kinetic constant is much higher than values that are reported in literature for GEM thermal release [79], demonstrating the improvement of the GEM release with the application of the AC field.

In fact, the release of GEM at $43^{\circ} \mathrm{C}$ (temperature controlled without field applied) showed a faster release profile than at $37^{\circ} \mathrm{C}$, reaching a plateau of $90 \%$ of the drug after $48 \mathrm{~h}$, when compared to the $35 \%$ released at $37{ }^{\circ} \mathrm{C}$ after the same time. Only $40 \%$ of the total drug was released at $37^{\circ} \mathrm{C}$ after six days. Longer time is needed to release the complete amount of drug at physiological temperature, resulting in a negligible release rate. The release dependences found at both $37^{\circ} \mathrm{C}$ and $43^{\circ} \mathrm{C}$ are well described by first order kinetics, according to Equation (5):

$$
R(0)-R(t)=R(0)\left(1-e^{-k_{1} t}\right)
$$

where $k_{1}$ is the first order rate constant. Its best fit values are $0.092 \mathrm{~h}^{-1}$ and $0.056 \mathrm{~h}^{-1}$ for 37 and $43{ }^{\circ} \mathrm{C}$, respectively. Note that in a first order release profile the process is directly proportional to the drug concentration that is involved in the process, whereas in a zeroth-order release the drug is released at a constant rate, leading to the best control of plasma concentration and offering several advantages, including improved patient compliance and reduction in the frequency of drug administration [80,81]. This feature is also a positive result of using hyperthermia in combination with drug release.
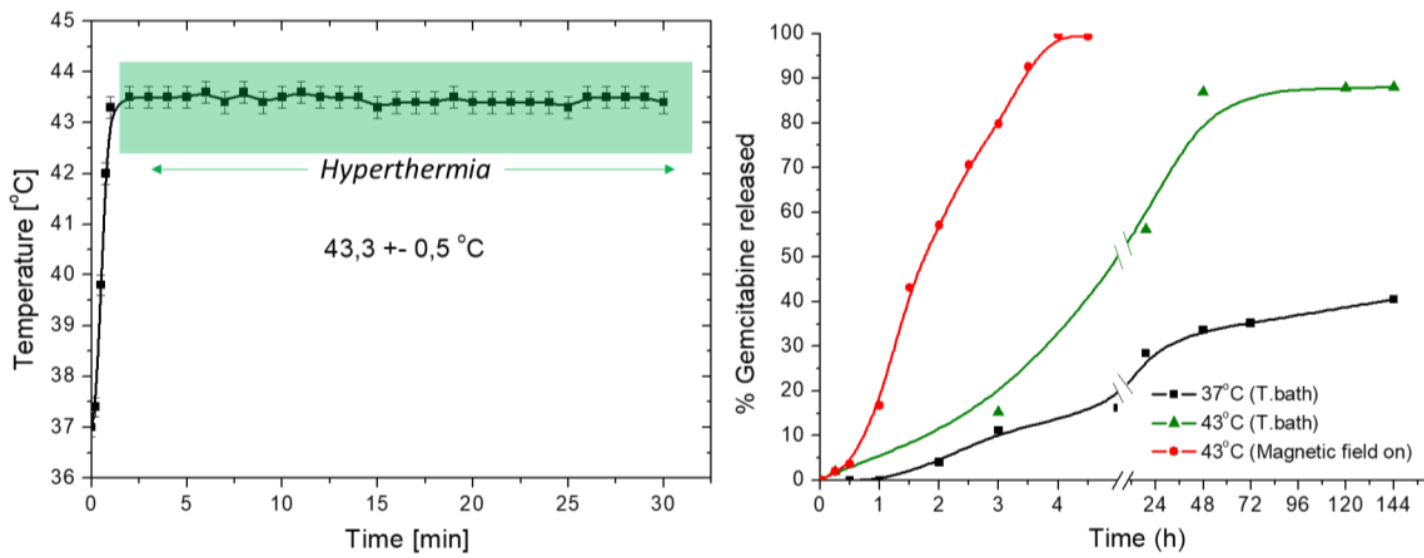

Figure 9. (a) Typical hyperthermia and drug release experiment with manually stabilized magnetic field strength; (b) GEM release profile for thermostatic bath at $37^{\circ} \mathrm{C}, 43^{\circ} \mathrm{C}$, and magnetic field hyperthermia set at $43{ }^{\circ} \mathrm{C}$.

\section{Conclusions}

The combination of drug release and magnetic hyperthermia using magnetic nanoparticles consisting of a magnetite core and a polymer envelope is investigated for modified commercial particles in which the $-\mathrm{OH}$ terminated co-polymer is modified to make it $-\mathrm{COOH}$ terminated. The particles are found to be quite monodisperse in size and spherical in shape, with negative zeta potential in physiological $\mathrm{pH}$ conditions. They showed a very significant hyperthermia response, with SAR values of up to $45 \mathrm{~W} / \mathrm{g}$. Gemcitabine hydrochloride was absorbed by contact in solution between the particles and the drug. The loading was optimal at a rate of $33.3 \mathrm{mg}$ GEM/g MNPs, and is demonstrated by 
IR spectrometry and electrophoresis. The drug release in PBS at $\mathrm{pH} 7.4$ was investigated in three experimental conditions: temperature that was maintained at $37^{\circ} \mathrm{C}$ or $43^{\circ} \mathrm{C}$ in a temperature controlled bath, and hyperthermia-triggered release at $43^{\circ} \mathrm{C}$. It is demonstrated that drug delivery in the latter case proceeds at zeroth order kinetics and the magnetic field exposure triggers and improves the release significantly, reaching $100 \%$ delivery in less than $4 \mathrm{~h}$.

Acknowledgments: This research work is supported by MINECO Ramón y Cajal programme (RYC-2014-16901); Junta de Andalucía (PE2012-FQM694) and Feder Funds UE.

Author Contributions: G. R. Iglesias and Angel V. Delgado conceived, designed the experiments and wrote the paper; Felisa Reyes-Ortega and B. L. Checa Fernández performed the experiments and analyzed the data.

Conflicts of Interest: The authors declare no conflict of interest.

\section{References}

1. Mitragotri, S.; Lahann, J. Physical approaches to biomaterial design. Nat. Mater. 2009, 8, 15-23. [CrossRef] [PubMed]

2. Suresh, S. Nanomedicine-Elastic clues in cancer detection. Nat. Nanotechnol. 2007, 2, 748-749. [CrossRef] [PubMed]

3. Whitesides, G.M. The 'right' size in nanobiotechnology. Nat. Biotechnol. 2003, 21, 1161-1165. [CrossRef] [PubMed]

4. Carmona-Ribeiro, A.M. Biomimetic nanoparticles: Preparation, characterization and biomedical applications. Int. J. Nanomed. 2010, 5, 249-259. [CrossRef]

5. Thanh, N.T.K.; Green, L.A.W. Functionalisation of nanoparticles for biomedical applications. Nano Today 2010, 5, 213-230. [CrossRef]

6. Kim, E.M.; Jeong, H.J. Current Status and Future Direction of Nanomedicine: Focus on Advanced Biological and Medical Applications. Nucl. Med. Mol. Imaging 2017, 51, 106-117. [CrossRef] [PubMed]

7. Liu, J.R.; Wang, X.J.; Tang, X.; Hong, R.Y.; Wang, Y.Q.; Feng, W.G. Preparation and characterization of carbonyl iron/strontium hexaferrite magnetorheological fluids. Particuology 2015, 22, 134-144. [CrossRef]

8. Singh, A.; Sahoo, S.K. Magnetic nanoparticles: A novel platform for cancer theranostics. Drug Discov. Today 2014, 19, 474-481. [CrossRef] [PubMed]

9. Kim, C.S.; Tonga, G.Y.; Solfiell, D.; Rotello, V.M. Inorganic nanosystems for therapeutic delivery: Status and prospects. Adv. Drug Deliv. Rev. 2013, 65, 93-99. [CrossRef] [PubMed]

10. Laurent, S.; Bridot, J.L.; Elst, L.V.; Muller, R.N. Magnetic iron oxide nanoparticles for biomedical applications. Futur. Med. Chem. 2010, 2, 427-449. [CrossRef] [PubMed]

11. Duran, J.D.G.; Arias, J.L.; Gallardo, V.; Delgado, A.V. Magnetic colloids as drug vehicles. J. Pharm. Sci. 2008, 97, 2948-2983. [CrossRef] [PubMed]

12. McBain, S.C.; Yiu, H.H.P.; Dobson, J. Magnetic nanoparticles for gene and drug delivery. Int. J. Nanomed. 2008, 3, 169-180.

13. Laurent, D.F.S.; Port, M.; Roch, A.; Robic, C.; Elst, L.V.; Muller, R.N. Magnetic Iron Oxide Nanoparticles: Synthesis, Stabilization, Vectorization, Physicochemical Characterizations, and Biological Applications. Chem. Rev. 2008, 108, 2064-2110. [CrossRef] [PubMed]

14. Gupta, A.K.; Naregalkar, R.R.; Vaidya, V.D.; Gupta, M. Recent advances on surface engineering of magnetic iron oxide nanoparticles and their biomedical applications. Nanomedicine 2007, 2, 23-39. [CrossRef] [PubMed]

15. Dobson, J. Magnetic nanoparticles for drug delivery. Drug Dev. Res. 2006, 67, 55-60. [CrossRef]

16. Tartaj, P.; Morales, M.P.; Gonzalez-Carreno, T.; Veintemillas-Verdaguer, S.; Serna, C.J. Advances in magnetic nanoparticles for biotechnology applications. J. Magn. Magn. Mater. 2005, 290, 28-34. [CrossRef]

17. Berry, C.C.; Curtis, A.S.G. Functionalisation of magnetic nanoparticles for applications in biomedicine. J. Phys. D-Appl. Phys. 2003, 36, R198-R206. [CrossRef]

18. Angelakeris, M. Magnetic nanoparticles: A multifunctional vehicle for modern theranostics. Biochim. Biophys. Acta-Gen. Subj. 2017, 1861, 1642-1651. [CrossRef] [PubMed]

19. Iglesias, G.R.; Ruiz-Moron, L.F; Duran, J.D.G.; Delgado, A.V. Dynamic and wear study of an extremely bidisperse magnetorheological fluid. Smart Mater. Struct. 2015, 24, 127001. [CrossRef] 
20. Estelrich, J.; Escribano, E.; Queralt, J.; Busquets, M.A. Iron Oxide Nanoparticles for Magnetically-Guided and Magnetically-Responsive Drug Delivery. Int. J. Mol. Sci. 2015, 16, 8070-8101. [CrossRef] [PubMed]

21. Delgado, A.V.; López-Viota, J.; Ramos-Tejada, M.M.; Arias, J.L. Particle geometry, charge, and wettability: The fate of nanoparticle-based drug vehicles. In Colloid and Interface Science in Pharmaceutical Research and Development; Oshima, H., Makino, K., Eds.; Elsevier B.V.: Amsterdam, The Netherlands, 2014; Volume 1, pp. 443-467.

22. Klostergaard, J.; Seeney, C.E. Magnetic nanovectors for drug delivery. Nanomed.-Nanotechnol. Biol. Med. 2012, 8, S37-S50. [CrossRef] [PubMed]

23. Yao, L.; Xu, S.J. Detection of magnetic nanomaterials in molecular imaging and diagnosis applications. Nanotechnol. Rev. 2014, 3, 247-268. [CrossRef]

24. Arami, H.; Stephen, Z.; Veiseh, O.; Zhang, M. Chitosan-Coated Iron Oxide Nanoparticles for Molecular Imaging and Drug Delivery. In Chitosan for Biomaterials I; Jayakumar, R., Prabaharan, M., Muzzarelli, R.A.A., Eds.; Springer: Berlin/Heidelberg, Germany, 2011; pp. 163-184.

25. Wang, Y.X. Superparamagnetic iron oxide based MRI contrast agents: Current status of clinical application. Quant. Med. Imaging Surg. 2011, 1, 6.

26. Hong, R.Y.; Feng, B.; Chen, L.L.; Liu, G.H.; Li, H.Z.; Zheng, Y.; Wei, D.G. Synthesis, characterization and MRI application of dextran-coated $\mathrm{Fe}_{3} \mathrm{O}_{4}$ magnetic nanoparticles. Biochem. Eng. J. 2008, 42, 290-300. [CrossRef]

27. Deatsch, A.E.; Evans, B.A. Heating efficiency in magnetic nanoparticle hyperthermia. J. Magn. Magn. Mater. 2014, 354 (Suppl. C), 163-172. [CrossRef]

28. Wildeboer, R.R.; Southern, P.; Pankhurst, Q.A. On the reliable measurement of specific absorption rates and intrinsic loss parameters in magnetic hyperthermia materials. J. Phys. D-Appl. Phys. 2014, 47, 495003. [CrossRef]

29. Ortega, D.; Pankhurst, Q.A. Magnetic hyperthermia. In Nanoscience Volume 1: Nanostructure through Chemistry; O’Brien, P., Ed.; Royal Society of Chemistry: Cambridge, UK, 2013; Volume 1, pp. 60-88.

30. Kobayashi, T. Cancer hyperthermia using magnetic nanoparticles. Biotechnol. J. 2011, 6, 1342-1347. [CrossRef] [PubMed]

31. Laurent, S.; Dutz, S.; Hafeli, U.O.; Mahmoudi, M. Magnetic fluid hyperthermia: Focus on superparamagnetic iron oxide nanoparticles. Adv. Colloid Interface Sci. 2011, 166, 8-23. [CrossRef] [PubMed]

32. Lee, H.; Kim, S.; Choi, B.H.; Park, M.T.; Lee, J.; Jeong, S.Y.; Choi, E.K.; Lim, B.U.; Kim, C.; Park, H.J. Hyperthermia improves therapeutic efficacy of doxorubicin carried by mesoporous silica nanocontainers in human lung cancer cells. Int. J. Hyperth. 2011, 27, 698-707. [CrossRef] [PubMed]

33. Li, Z.X.; Kawashita, M.; Araki, N.; Mitsumori, M.; Hiraoka, M.; Doi, M. Magnetite nanoparticles with high heating efficiencies for application in the hyperthermia of cancer. Mater. Sci. Eng. C Mater. Biol. Appl. 2010, 30, 990-996. [CrossRef]

34. Aqil, A.; Vasseur, S.; Duguet, E.; Passirani, C.; Benoit, J.P.; Jerome, R.; Jerome, C. Magnetic nanoparticles coated by temperature responsive copolymers for hyperthermia. J. Mater. Chem. 2008, 18, 3352-3360. [CrossRef]

35. Hergt, R.; Dutz, S. Magnetic particle hyperthermia-biophysical limitations of a visionary tumour therapy. J. Magn. Magn. Mater. 2007, 311, 187-192. [CrossRef]

36. Rosensweig, R.E. Heating magnetic fluid with alternating magnetic field. J. Magn. Magn. Mater. 2002, 252, 370-374. [CrossRef]

37. Falk, M.H.; Issels, R.D. Hyperthermia in oncology. Int. J. Hyperth. 2001, 17, 1-18. [CrossRef]

38. Pankhurst, Q.A.; Thanh, N.T.K.; Jones, S.K.; Dobson, J. Progress in applications of magnetic nanoparticles in biomedicine. J. Phys. D-Appl. Phys. 2009, 42, 220301. [CrossRef]

39. Pankhurst, Q.A.; Connolly, J.; Jones, S.K.; Dobson, J. Applications of magnetic nanoparticles in biomedicine. J. Phys. D-Appl. Phys. 2003, 36, R167-R181. [CrossRef]

40. Iglesias, G.; Delgado, A.V.; Kujda, M.; Ramos-Tejada, M.M. Magnetic hyperthermia with magnetite nanoparticles: Electrostatic and polymeric stabilization. Colloid Polym. Sci. 2016, 294, 1541-1550. [CrossRef]

41. Bonvin, D.; Bastiaansen, J.A.M.; Stuber, M.; Hofmann, H.; Ebersold, M.M. Folic acid on iron oxide nanoparticles: Platform with high potential for simultaneous targeting, MRI detection and hyperthermia treatment of lymph node metastases of prostate cancer. Dalton Trans. 2017, 46, 12692-12704. [CrossRef] [PubMed] 
42. Lima-Tenorio, M.K.; Pineda, E.A.G.; Ahmad, N.M.; Fessi, H.; Elaissari, A. Magnetic nanoparticles: In vivo cancer diagnosis and therapy. Int. J. Pharm. 2015, 493, 313-327. [CrossRef] [PubMed]

43. Lima, E., Jr.; Torres, T.E.; Rossi, L.M.; Rechenberg, H.R.; Berquo, T.S.; Ibarra, A.; Marquina, C.; Ibarra, M.R.; Goya, G.F. Size dependence of the magnetic relaxation and specific power absorption in iron oxide nanoparticles. J. Nanopart. Res. 2013, 15, 1654. [CrossRef]

44. Long, N.V.; Yang, Y.; Teranishi, T.; Thi, C.M.; Cao, Y.; Nogami, M. Biomedical Applications of Advanced Multifunctional Magnetic Nanoparticles. J. Nanosci. Nanotechnol. 2015, 15, 10091-10107. [CrossRef] [PubMed]

45. Kumar, C.; Mohammad, F. Magnetic nanomaterials for hyperthermia-based therapy and controlled drug delivery. Adv. Drug Deliv. Rev. 2011, 63, 789-808. [CrossRef] [PubMed]

46. Kaviti, A.K.; Yadav, A.; Shukla, A. Inclined solar still designs: A review. Renew. Sustain. Energy Rev. 2016, 54, 429-451. [CrossRef]

47. Soares, P.I.P.; Sousa, A.I.; Silva, J.C.; Ferreira, I.M.M.; Novo, C.M.M.; Borges, J.P. Chitosan-based nanoparticles as drug delivery systems for doxorubicin: Optimization and modelling. Carbohydr. Polym. 2016, 147, 304-312. [CrossRef] [PubMed]

48. Soares, P.I.P.; Sousa, A.I.; Ferreira, I.M.M.; Novo, C.M.M.; Borges, J.P. Towards the development of multifunctional chitosan-based iron oxide nanoparticles: Optimization and modelling of doxorubicin release. Carbohydr. Polym. 2016, 153, 212-221. [CrossRef] [PubMed]

49. Quinto, C.A.; Mohindra, P.; Tong, S.; Bao, G. Multifunctional superparamagnetic iron oxide nanoparticles for combined chemotherapy and hyperthermia cancer treatment. Nanoscale 2015, 7, 12728-12736. [CrossRef] [PubMed]

50. Iglesias, G.R.; Delgado, A.V.; Gonzalez-Caballero, E.; Ramos-Tejada, M.M. Simultaneous hyperthermiaand doxorubicindelivery frompolymer-coatedmagnetitenanoparticles. J. Magn. Magn. Mater. 2017, 431, $294-296$. [CrossRef]

51. Eckel, F.; Schmid, R.M. Chemotherapy in advanced biliary tract carcinoma: A pooled analysis of clinical trials. Br. J. Cancer 2007, 96, 896-902. [CrossRef] [PubMed]

52. Kamat, A.M.; Hahn, N.M.; Efstathiou, J.A.; Lerner, S.P.; Malmstrom, P.U.; Choi, W.; Guo, C.C.; Lotan, Y.; Kassouf, W. Bladder cancer. Lancet 2016, 388, 2796-2810. [CrossRef]

53. Kaufman, D.S.; Shipley, W.U.; Feldman, A.S. Bladder cancer. Lancet 2009, 374, 239-249. [CrossRef]

54. Conroy, T.; Bachet, J.B.; Ayav, A.; Huguet, F.; Lambert, A.; Caramella, C.; Marechal, R.; van Laethem, J.L.; Ducreux, M. Current standards and new innovative approaches for treatment of pancreatic cancer. Eur. J. Cancer 2016, 57, 10-22. [CrossRef] [PubMed]

55. Ettinger, D.S.; Akerley, W.; Bepler, G.; Blum, M.G.; Chang, A.; Cheney, R.T.; Chirieac, L.R.; D'Amico, T.A.; Demmy, T.L.; Ganti, A.K.P.; et al. Non Small Cell Lung Cancer. J. Nat. Compr. Cancer Netw. 2010, 8, 740-801. [CrossRef]

56. Khare, V.; Singh, A.; Mahajan, G.; Alam, N.; Kour, S.; Gupta, M.; Kumar, A.; Singh, G.; Singh, S.K.; Saxena, A.K.; et al. Long-circulatory nanoparticles for gemcitabine delivery: Development and investigation of pharmacokinetics and in vivo anticancer efficacy. Eur. J. Pharm. Sci. 2016, 92, 183-193. [CrossRef] [PubMed]

57. Celia, C.; Cosco, D.; Paolino, D.; Fresta, M. Gemcitabine-loaded innovative nanocarriers vs. GEMZAR: Biodistribution, pharmacokinetic features and in vivo antitumor activity. Expert Opin. Drug Deliv. 2011, 8, 1609-1629. [CrossRef] [PubMed]

58. Di Marco, M.; di Cicilia, R.; Macchini, M.; Nobili, E.; Vecchirelli, S.; Brandi, G.; Biasco, G. Metastatic pancreatic cancer: Is gemcitabine still the best standard treatment? (Review). Oncol. Rep. 2010, 23, 1183-1192. [CrossRef] [PubMed]

59. Pérez-Manga, G.; Lluch, A.; Alba, E.; Moreno-Nogueira, J.A.; Palomero, M.; García-Conde, J.; Khayat, D.; Rivelles, N. Gemcitabine in Combination with Doxorubicin in Advanced Breast Cancer: Final Results of a Phase II Pharmacokinetic Trial. J. Clin. Oncol. 2000, 18, 2545-2552. [CrossRef] [PubMed]

60. Storm, G.; Belliot, S.O.; Daemen, T.; Lasic, D.D. Surface modification of nanoparticles to oppose uptake by the mononuclear phagocyte system. Target. Drugs Deliv. Syst. 1995, 17, 31-48. [CrossRef]

61. Sun, J.; Zhou, S.; Hou, P.; Yang, Y.; Weng, J.; Li, X.; Li, M. Synthesis and characterization of biocompatible $\mathrm{Fe}_{3} \mathrm{O}_{4}$ nanoparticles. J. Biomed. Mater. Res. A 2007, 80, 333-341. [CrossRef] [PubMed]

62. O'Brien, R.W.; White, L.R. Electrophoretic mobility of a spherical colloidal particle. J. Chem. Soc. Faraday Trans. II 1978, 74, 1607-1626. [CrossRef] 
63. Obaidat, I.M.; Issa, B.; Haik, Y. Magnetic Properties of Magnetic Nanoparticles for Efficient Hyperthermia. Nanomaterials 2015, 5, 63-89. [CrossRef] [PubMed]

64. Raikher, Y.L.; Stepanov, V.I. Physical aspects of magnetic hyperthermia: Low-frequency ac field absorption in a magnetic colloid. J. Magn. Magn. Mater. 2014, 368, 421-427. [CrossRef]

65. Schlorf, T.; Meincke, M.; Kossel, E.; Glueer, C.C.; Jansen, O.; Mentlein, R. Biological Properties of Iron Oxide Nanoparticles for Cellular and Molecular Magnetic Resonance Imaging. Int. J. Mol. Sci. 2011, 12, 12-23. [CrossRef] [PubMed]

66. Singh, R.; Shakya, A.K.; Naik, R.; Shalan, N. Stability-Indicating HPLC Determination of Gemcitabine in Pharmaceutical Formulations. Int. J. Anal. Chem. 2015, 2015, 862592. [CrossRef] [PubMed]

67. Viota, J.L.; Carazo, A.; Munoz-Gamez, J.A.; Rudzka, K.; Gomez-Sotomayor, R.; Ruiz-Extremera, A.; Salmeron, J.; Delgado, A.V. Functionalized magnetic nanoparticles as vehicles for the delivery of the antitumor drug gemcitabine to tumor cells. Physicochemical in vitro evaluation. Mater. Sci. Eng. C-Mater. Biol. Appl. 2013, 33, 1183-1192. [CrossRef] [PubMed]

68. Betsiou, M.; Bantsis, G.; Zoi, I.; Sikalidis, C. Adsorption and release of gemcitabine hydrochloride and oxaliplatin by hydroxyapatite. Ceram. Int. 2012, 38, 2719-2724. [CrossRef]

69. Khare, V.; Al Sakarchi, W.; Gupta, P.N.; Curtis, A.D.M.; Hoskins, C. Synthesis and characterization of TPGS-gemcitabine prodrug micelles for pancreatic cancer therapy. RSC Adv. 2016, 6, 60126-60137. [CrossRef]

70. Ayyappan, S.; Gnanaprakash, G.; Panneerselvam, G.; Antony, M.P.; Philip, J. Effect of Surfactant Monolayer on Reduction of $\mathrm{Fe}_{3} \mathrm{O}_{4}$ Nanoparticles under Vacuum. J. Phys. Chem. C 2008, 112, 18376-18383. [CrossRef]

71. Gałka, P.; Kowalonek, J.; Kaczmarek, H. Thermogravimetric analysis of thermal stability of poly(methyl methacrylate) films modified with photoinitiators. J. Therm. Anal. Calorim. 2014, 115, 1387-1394. [CrossRef]

72. Demirelli, K.; Coskun, M.; Kaya, E. A detailed study of thermal degradation of poly(2-hydroxyethyl methacrylate). Polym. Degrad. Stab. 2001, 72, 75-80. [CrossRef]

73. Han, S.; Hagiwara, M.; Ishizone, T. Synthesis of Thermally Sensitive Water-Soluble Polymethacrylates by Living Anionic Polymerizations of Oligo(ethylene glycol) Methyl Ether Methacrylates. Macromolecules 2003, 36, 8312-8319. [CrossRef]

74. Das, R.; Alonso, J.; Porshokouh, Z.N.; Kalappattil, V.; Torres, D.; Phan, M.H.; Garaio, E.; Garcia, J.A.; Llamazares, J.L.S.; Srikanth, H. Tunable High Aspect Ratio Iron Oxide Nanorods for Enhanced Hyperthermia. J. Phys. Chem. C 2016, 120, 10086-10093. [CrossRef]

75. Lu, H.M.; Zheng, W.T.; Jiang, Q. Saturation magnetization of ferromagnetic and ferrimagnetic nanocrystals at room temperature. J. Phys. D-Appl. Phys. 2007, 40, 320-325. [CrossRef]

76. Johannsen, M.; Gneveckow, U.; Eckelt, L.; Feussner, A.; Waldofner, N.; Scholz, R.; Deger, S.; Wust, P.; Loening, S.A.; Jordan, A. Clinical hyperthermia of prostate cancer using magnetic nanoparticles: Presentation of a new interstitial technique. Int. J. Hyperth. 2005, 21, 637-647. [CrossRef]

77. Johannsen, M.; Gneveckow, U.; Taymoorian, K.; Thiesen, B.; Waldoefner, N.; Scholz, R.; Jung, K.; Jordan, A.; Wust, P.; Loening, S.A. Morbidity and quality of life during thermotherapy using magnetic nanoparticles in locally recurrent prostate cancer: Results of a prospective phase I trial. J. Magn. Magn. Mater. 2007, 23, 315-323. [CrossRef] [PubMed]

78. Dash, S.; Murthy, P.N.; Nath, L.; Chowdhury, P. Kinetic modeling on drug release from controlled drug delivery systems. Acta Pol. Pharm.-Drug Res. 2010, 67, 217-223.

79. Jaidev, L.R.; Krishnan, U.M.; Sethuraman, S. Gemcitabine loaded biodegradable PLGA nanospheres for in vitro pancreatic cancer therapy. Mater. Sci. Eng. C Mater. Biol. Appl. 2015, 47, 40-47. [CrossRef] [PubMed]

80. Haley, B.; Frenkel, E. Nanoparticles for drug delivery in cancer treatment. Urol. Oncol. Sem. Orig. Investig. 2008, 26, 57-64. [CrossRef] [PubMed]

81. Karna, S.; Chaturvedi, S.; Agrawal, V.; Alim, M. Formulation approaches for sustained release dosage forms: A review. Asian J. Pharm. Clin. Res. 2015, 8, 46-53.

(C) 2018 by the authors. Licensee MDPI, Basel, Switzerland. This article is an open access article distributed under the terms and conditions of the Creative Commons Attribution (CC BY) license (http:/ / creativecommons.org/licenses/by/4.0/). 